\title{
Edificio Master: la tecnología audiovisual como escritura étnica
}

\section{Mazás, Fernando}

Resumen:

el presente artículo elabora sobre la relación indisociable entre el cuerpo y la palabra dicha como discurso productor de sentido en el medio audiovisual. El campo de estudio de esta elaboración será el film Edificio Master (2002) del director brasileño Eduardo Coutinho, ya que lo considero como un ejemplo superlativo en cuanto a la utilización del dispositivo de la entrevista en una película documental, y como a través del mismo, surgen de los personajes entrevistados dimensiones de sentido de una profundidad y complejidad inusitadas que transcienden los lugar comunes y estereotipos que están comúnmente asociados a este

Cuadernos del Centro de Estudios de Diseño y Comunicación Nº 62

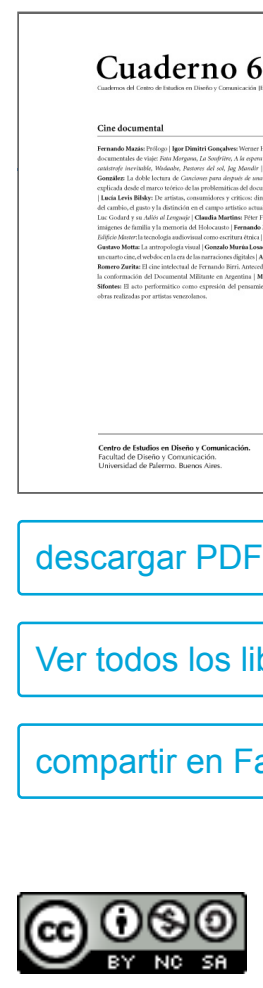

Esta obra está bajo una Licencia Creative Commons Atribución-NoComercialCompartirlgual 4.0 Internacional recurso. Finalmente, se reflexiona sobre esta modalidad particular de entrevista como la piedra angular de la etnografía audiovisual moderna y su impacto en la epistemología contemporánea que piensa y analiza al cine documental.

Palabras clave: cine documental - entrevista - etnografía audiovisual - Coutinho.

$\left({ }^{*}\right)$ Licenciado en Cinematografía con orientación en Dirección Cinematográfica por la Universidad del Cine (FUC) en donde actualmente está realizando la Maestría en Cine Documental. Docente de Semiología y Teoría de la Comunicación, Semiótica del Cine y Guión I en dicha universidad. Docente en la cátedra de Escritura Audiovisual de la Universidad de Belgrano.

Se tiende a pensar que la palabra es la palabra dicha o escrita, y que eso es todo. Sin embargo, cuando una persona habla desde el fondo de sí misma, o sea, cuando habla con sus vísceras, sale del lugar común impuesto por la sociedad y sus estructuras. Esto es lo que nos interesa, porque ahí la persona produce un habla original. El hombre es un animal que habla y lo hace a través de su cuerpo. ¿Qué es, pues, lo que el hombre tiene de seguro? Lo único que hay de real, tanto en la vida como en el cine, es la apariencia, un cuerpo que 
existe y que habla. Sin la apariencia, sin lo físico, uno no puede filosofar ni hacer nada. (Eduardo Coutinho) En la introducción a su libro seminal Las palabras y las cosas, Michel Foucault celebra el advenimiento y la difusión de dos nuevas disciplinas que habrían de revolucionar las prácticas cognitivas del siglo XX: estas son el psicoanálisis y la etnografía. Lo que para el pensador francés estas disciplinas tendrían en común sería la puesta en crisis del paradigma positivista instaurado a partir del siglo XIX. La ruptura fundamental que plantea Foucault tanto del Psicoanálisis con respecto a la Psicología como discurso científico y de la Etnografía con respecto a la Antropología clásica es que ambas disciplinas se apartan de una concepción universal de Hombre como modelo universal, justamente Antropológico, para pasar a concentrarse en la investigación y el estudio de procesos singulares y locales, históricamente construidos que dejan de lado toda pretensión de universalidad. Es por eso que este tipo de experiencias de conocimiento no pueden, ni pretenden, ser consideradas como prácticas humanistas, sino que están orientadas a la aparición de lo nuevo, lo que en términos de pensamiento supone la puesta en crisis de las categorías tradicionales a partir de las cuales construimos e interpretamos al mundo.

Este es el marco que tomo como punto de partida para el análisis del film Edificio Master (2003) de Eduardo Coutinho, film de gran sencillez formal y difícil clasificación en las categorías taxonómicas de la teoría documental y que lo acercan mucho al trabajo de campo etnográfico, sobre todo a los procedimientos descriptos en el libro de Rosana Guber. Pero es justamente en este punto, en la confluencia e interacción entre la estética audiovisual y la práctica etnográfica donde surge la singularidad de este trabajo. Consideramos que este film tiene una forma tan particular de articular discurso que culmina produciendo una nueva forma hibrida que desafía tanto a la forma tradicional de hacer cine como a la práctica tradicional de la etnografía, forma a la que en este artículo vamos a darle el nombre de escritura o inscripción étnica y que fundamentalmente es otra forma creativa y original de formular la eterna pregunta por la alteridad.

Como señala Marcos Da Silva en su artículo sobre Edificio Master, hay ciertos aspectos del film que sirven como ejemplo de un nuevo modo de investigación en el campo de la antropología fílmica. Las entrevistas no responden a un mero registro o una versión audiovisual de una etnografía escrita, ni a la confirmación de un "haber estado allí" como documento ilustrativo de un trabajo antropológico. Se trata en cambio de pensar en una situación que se podría llamar encuentro etnográfico como una verdadera performance entre dos sujetos.

Por un lado el cineasta, que deja entrever su intervención directa en la producción del texto, desde el manejo de la tecnología hasta la aparición de su propia voz como evidencia de su intervención en el territorio fílmico, y por el otro un segundo sujeto (ya no se trata de un objeto) que más allá de ser el entrevistado, se transforma en un personaje que construye su propio texto de acuerdo con sus propias experiencias subjetivas, que sirven en este caso de contexto fundante del relato que el cineasta intenta construir. Lo performativo (en un sentido que no se aparta demasiado de la modalidad representacional propuesta por Bill Nichols) se da en la forma en como los personajes entrevistados se ponen en escena a sí mismos en su hábitat expresando su identidad con actividades corporales, materiales y rituales. De esta manera se privilegia el contenido relacional de las vivencias humanas como productoras de sentido, más allá de los contenidos apriorísticos que explican una cultura y justifican los comportamientos humanos como procesos relacionales cotidianos.

Es lo que Francois Niney llamaría una autentica experiencia de enunciación dialógica, modelo narrativo que surge de la especificidad del texto documental. 
Por más realista y transparente que parezca ser, ninguna filmación es gratuita y descomprometida.

Filmar y ser filmado implica la utilización de lenguajes que sobrepasan la simple conversación para transformarse en verdaderas performances que acompañan la relación de los seres humanos con su medio. Por eso una antropología de las relaciones del ser humano y su ambiente nos lleva a considerar a la producción fílmica más allá de un instrumento de captación y reproducción de realidad, sino que utilizado de esta manera el audiovisual se transforma en un dispositivo con poderes demiúrgicos, capaz de inventar mundos que se constituyen a partir relaciones creadas por la cámara y la puesta en escena.

Allí es donde encontramos que desde una perspectiva lingüística, en el film de Coutinho hay una relación directa entre lo performativo y por supuesto lo ritual y lo teatral.

Semiológicamente, el teatro es un sistema de signos en el cual signos vivos, icónicos y no simbólicos son los mismos signos que en la realidad. El teatro representa a un cuerpo con un cuerpo, a un objeto con un objeto, a una acción con una acción. Es decir, desde un punto de vista puramente semiológico no difiere (al igual que el cine) del sistema de signos de la realidad. El arquetipo semiológico del teatro es la performance que tiene lugar cada día delante de nuestros ojos y al alcance de nuestros oídos, en la calle, en nuestro hogar, en espacios públicos, etc. En este sentido la realidad social es una representación que no es completamente inconsciente de su estatus de representación. Por consiguiente tiene sus propios códigos: modales, comportamientos, lenguaje corporal, etc. Dicho de otra manera, no es completamente inconsciente de su estatus de rito. Ergo, el rito arquetípico del teatro es un rito natural. Y esto es lo que ocurre en Edificio Master: cada departamento es un teatro donde sus habitantes se ponen en escena a ellos mismos y se despliegan como personajes. Y es esa relación misma, en su acto performativo, la que crea a los sujetos.

Coincidimos plenamente con la ensayista Consuelo Lins cuando propone al cine de Eduardo Coutinho como un cine de la palabra filmada, y que apuesta por las potencialidades narrativas de las personas entrevistadas. Coutinho es un crítico obstinado de cierta teoría que afirma que el cine es esencialmente imagen, de un pensamiento estrecho que no ve la riqueza y la complejidad de la imagen y del sonido de la palabra del otro: "los silencios, tropiezos, ritmos, inflexiones, retomadas diferenciadas del discurso. Los gestos, el fruncir de los labios y cejas, las miradas, los suspiros, el movimiento de los hombros, etc". Algo siempre se está construyendo entre la palabra y la escucha que no pertenece ni al entrevistado ni al entrevistador y que al mismo tiempo remite a un fuera de campo virtual que no cesa de transformarse. Allí los personajes formulan ideas, fabulan y se inventan, y nosotros aprendemos con ellos así como ellos también aprenden sobre sus propias vidas.

Es un proceso en el cual se da un corto-circuito entre la persona y el personaje que va siendo creado en el acto de hablar.

Si es el rodaje que genera condiciones para el surgimiento de esa palabra que fabula, el proceso de montaje es igualmente esencial para mantener su singularidad. No hay, en ningún momento, una generalización, una clasificación. Las personas que hablan no son exhibidas como ejemplos de nada. Trascienden cualquier estereotipo psicosocial (el loco, el marginal, la prostituta, los enamorados). Los personajes no forman parte de una estadística, ni están allí para justificar o probar una idea central. En fin, las personas no son vistas como parte de un todo. Esto se debe a una habilidad muy precisa que tiene Coutinho como entrevistador (algo que marca como muy importante Rosana Guber en su libro sobre las técnicas etnográficas) que es la capacidad que 
tiene el director para, a través de una escucha sumamente atenta formular en el momento adecuado la pregunta hermenéutica precisa: a Coutinho como entrevistador no le interesa si lo que dice el entrevistado es verdadero, falso, moral o inmoral, sino que la focalización está puesta en que quiere decir con lo que está diciendo mi interlocutor. Pero es una extraña hermenéutica ya que a diferencia del fenomenólogo o el psicoanalista, no busca desentrañar ningún núcleo noemático o edípico de la subjetividad productora del discurso, sino que lo que busca es abrir el juego para que el discurso se expanda y multiplique rizomáticamente a otros espacios-tiempos, que más que desentrañar una verdad oculta del personaje, buscan potenciar la experiencia de un presente crónico y expandido.

Esta habilidad del entrevistador deriva de un posicionamiento fundamental que tiene que ver con la suspensión del sistema de juicio en beneficio de un acto de fabulación, que se expresa como pura potencia creadora. Esta premisa o mejor dicho anti-premisa moral es la que define el estatuto particular de la narración de Edificio Master. Abordando ahora la perspectiva que Gilles Deleuze desarrolla en La Imagen-Tiempo sobre la situación de narración cinematográfica en el cine moderno como potencia de lo falso, podríamos aplicar el mismo principio al film de Coutinho. En este caso también, y esto es especialmente llamativo en un tipo de film que tradicionalmente sería considerado como "documental", la narración deja de ser verídica, es decir de aspirar a lo verdadero para hacerse esencialmente falsificante. No es en absoluto "cada uno con su verdad", es decir, una variabilidad referida al contenido. Una potencia de lo falso reemplaza y desentroniza a la forma de lo verdadero, pues plantea la simultaneidad de presentes incomposibles o la coexistencia de pasados no necesariamente verdaderos. El hombre verídico muere, todo modelo de verdad se derrumba en provecho de una nueva narración. De esta forma se quiebra el sistema de juicio y las situaciones particulares son llevadas a una potencia que va más allá del bien y del mal (ej: secuencia de la joven que tuvo que prostituirse para mantener a su hijo).

Del film se desprende una idea de mundo que coincide con los puntos principales de la crítica de la verdad en Nietzche: el "mundo verdadero" no existe, y si existiera sería inaccesible, inevocable, y si fuera evocable sería inútil, superfluo. El mundo verdadero supone un "Hombre verídico", un hombre que quiere la verdad, pero este hombre tiene unos móviles muy extraños, como si dentro de si escondiera a otro hombre, una venganza.

Finalmente el hombre verídico no quiere otra cosa que juzgar la vida; erige un valor superior, el bien, en nombre del cual podrá juzgar; tiene sed de juzgar, ve en la vida un mal, una falta que hay que expiar: origen moral de la noción de verdad. A la manera de Nietzche, Coutinho confronta directamente al sistema de juicio: no hay valor superior a la vida, la vida no tiene que ser juzgada ni justificada, es inocente, tiene la "inocencia del devenir", está más allá del bien y del mal.

Si el ideal de verdad se derrumba, las relaciones de la apariencia ya no bastarán para mantener la posibilidad del juicio. Según términos de Nietzche, "al mismo tiempo que el mundo verdadero, hemos abolido también el mundo de las apariencias". Luego del derrumbe, solo quedan los cuerpos, que son fuerzas. Pero la fuerza ya no se vincula con un centro y tampoco enfrenta un medio o unos obstáculos. Solo enfrenta a otras fuerzas, a las que ella afecta o por la que es afectada. Esto hace que la narración entera no cese de modificarse en cada una de sus episodios, ya no de acuerdo a variaciones subjetivas sino según lugares desconectados y momentos descronologizados. La estructura del tipo mosaico (secuencias autónomas e intercambiables entre sí sin tener un orden estructural fijo en el film) que Comolli le atribuye a Wiseman se aplica directamente al relato del film. Cada departamento supone un micro-film que mantiene una autonomía con respecto al otro y son sucesos que pudieron acontecer antes, después o en simultáneo con respecto a los otros. Ya no se trata de juzgar la vida en 
nombre de una instancia superior que sería el bien, lo verdadero; se trata, por el contrario, de evaluar el ser, la acción, la pasión, el valor, cualesquiera que sean, en función de la vida que implican. El afecto como evaluación inmanente en lugar del juicio como valor trascendente: "yo amo o yo detesto" en lugar de "yo juzgo".

Si bien ya no se podría hablar más del bien y del mal, existe lo bueno y lo malo, lo noble y lo vil. Según los físicos, la energía noble es aquella capaz de transformarse, mientras que la vil ya no puede. De los dos lados hay voluntad de potencia, pero esta, no es más que un querer dominar en el devenir, agotado de la vida, mientras que ella es un querer -artista o "Virtud que da", creación de nuevas posibilidades en el devenir en surgimiento. Los hombres llamados superiores son viles o malos. La potencia creadora es en esencia generosa, adopta las metamorfosis de la vida y opone el devenir a la historia. Inconmensurable a todo juicio tiene la inocencia del devenir.

De acuerdo con Alain Badiou, una verdad absoluta es un evento que trasciende largamente la capacidad cognitiva del Sujeto ya que en su totalidad esta pertenece a la orden del Ser. Lo que el Sujeto puede percibir son tan sólo los signos que refieren a esa verdad que lo excede cuyo origen fuera de la dimensión espaciotemporal. A partir de esta apreciación, el autor introducía la siguiente paradoja: el mal, en este caso bajo la forma de la mentira, no significa la ausencia de verdad, sino por el contrario es inmanente a ésta y se da cuando una verdad, siempre parcial, es instrumentada para presentarse como una verdad total, universal. Es un ejemplo de doble negación hegeliana. "La paradoja está en que el mal está constituido por un exceso de verdad". Esta operación de universalización arbitraria y violenta de la verdad es uno de los pilares de las políticas totalitarias. No es otra cosa que el colonialismo, el verdadero rostro de la concepción actual de la globalización. La nueva y verdadera universalidad sólo podrá ser alcanzada por un diálogo o puesta en relación entre los nuevos sujetos políticos todavía no constituidos, para lo cual es necesario "regresar" a ese momento originario (contemporáneo al presente) donde no hay un todo sino un principio de multiplicidad. Este nuevo comienzo daría lugar a una multiplicidad real de sujetos que reemplazaría a la multiplicidad aparente que consiste en una imagen indirecta de fragmentación de un mismo y único sujeto que restituye un todo.

Al liberar lo falso de la potencia, la vida se liberaba de las apariencias tanto como de la verdad: ni verdadero ni falso, alternativa indecidible, sino potencia de lo falso, voluntad decisoria. Solo el artista creador lleva la potencia de lo falso a un grado que se efectúa, no en la forma sino en la transformación. Ya no hay verdad ni apariencia. Ya no hay forma invariable ni punto de vista variable sobre una forma. Hay un punto de vista que pertenece a la cosa hasta el extremo que la cosa no cesa de transformarse en un devenir que es idéntico al punto de vista. Metamorfosis de lo verdadero. Eso es lo que el artista, "Creador de verdad", pues la verdad no tiene que ser alcanzada, hallada ni reproducida, debe ser creada.

El relato ya no remite a un ideal de lo verdadero, que constituye su veracidad, sino que se convierte en un "seudorrelato", en un poema, en un relato que simula o más bien en una simulación del relato. Las imágenes objetivas y subjetivas pierden su distinción, pero también su identificación, en beneficio de un nuevo circuito donde se reemplazan en bloque, o bien se contaminan, o bien se descomponen y se recomponen. La ruptura no esta entre la ficción y la realidad sino en el nuevo modo de relato que las afecta a ambas. Si la alternativa real ficticio queda tan completamente superada, es porque la cámara en lugar de tallar un presente, ficticio o real, liga constantemente al personaje al antes y al después. Es preciso que el personaje sea primero real, para que afirme la ficción como una potencia y no como un modelo: es preciso que se ponga a fabular para afirmarse tanto más como real que como ficticio. El personaje no cesa de hacerse otro, y ya no es separable de ese 
devenir que se confunde con un pueblo. Lo que decimos del personaje también es válido para el propio cineasta. También él se hace otro, en la medida en la medida en que toma personajes reales como intercesores y reemplaza sus ficciones por sus propias fabulaciones, pero en cambio él le da a estas fabulaciones, la figura de leyendas, las somete a la "puesta en leyenda".

La célebre fórmula del cine documental: "lo cómodo es que uno sabe quién es, y a quién filma", pierde validez. La forma de identidad Yo $=$ Yo (o en su forma degenerada Ellos $=$ Ellos) cesa de valer para los personajes y para el cineasta, en lo real tanto como en la ficción. Lo que se deja adivinar es más bien, en grados profundos, el "Yo es Otro" de Rimbaud, que cuando exclama "soy de raza inferior desde la eternidad... Soy una bestia... Un negro...", lo hace pasando por toda una serie de falsarios, "comerciante eres un negro, magistrado eres un negro, general eres un negro, emperador cascarrabias eres un negro...", hasta esa más elevada potencia de lo falso que hace que un negro tenga que hacerse el mismo negro a través de sus roles blancos, mientras que el blanco encuentra en ello una posibilidad de hacerse negro también. "Yo es otro" es la formación de un relato simulante, de una simulación de relato o de un relato de simulación que destituye a la forma del relato veraz, situación que tradicionalmente era impensable buscar en el cine documental.

En Edificio Master, esta subjetividad indirecta libre que funciona como sujeto de la enunciación de la narración falsificante tiene origen en el modo sumamente específico y singular que se tiene de la práctica de la entrevista y del estatuto que adquiere la palabra dicha.

Para pensar la particular forma sobre cómo se articula y desarrolla el uso de la voz en el relato del film, tomaremos como marco teórico la perspectiva semiológica del lingüista ruso Mikhail Bakhtin en relación con el trabajo que Michel Chion y Gilles Deleuze desarrollan en relación al problema de la voz en el cine. El cine mudo ponía el acto de habla en estilo indirecto, porque lo hacía leer como título intermedio; la esencia del parlante, en cambio, reside en llevar el acto de habla al estilo directo, y en hacerlo interactuar con la imagen visual, manteniendo al mismo tiempo su pertenencia a esta imagen, incluso en la voz en off. Pero he aquí que, con el cine moderno, surge una utilización singularísima de la voz, que podríamos llamar estilo indirecto libre y que desborda la oposición entre lo directo y lo indirecto. No es una mezcla de indirecto y directo, sino una dimensión original, irreductible, que puede asumir diversas formas.

Si es verdad que el cine moderno implica el derrumbe del esquema sensoriomotor, el acto de habla ya no se inserta en el encadenamiento de acciones y reacciones ni revela una trama de interacciones. Se repliega sobre sí mismo, ya no es una dependencia o una pertenencia de la imagen visual, pasa a ser una imagen sonora de pleno derecho, cobra una autonomía cinematográfica, y el cine se hace verdaderamente audiovisual. Con este modo de utilización de lo parlante es el acontecimiento lo que la palabra debe remontar desde adentro para extraerle la parte espiritual de la que somos eternos contemporáneos: lo que constituye memoria o leyenda. El acto de habla se torna acto político de fabulación, acto moral de cuento, acto suprahistórico de leyenda.

En Edificio Master, los testimonios de los habitantes muchas veces se contradicen, y apuntan hacia un mundo heterogéneo, con múltiples direcciones. Los mundos revelados por el cineasta no están centrados en un comentario ni tampoco en informaciones precisas, sino en testimonios que se cruzan y tejen una red de pequeñas historias descentradas que se comunican a través de ligaciones frágiles y no causales. Son ecos que se establecen entre diferentes elementos de la imagen o del habla de los personajes. Lo que el espectador 
percibe es el resultado de una mezcla de personajes, hablas, sonidos ambientes, imágenes y expresiones, y nunca significaciones listas fornecidas por una voz en off.

Esta multiplicidad da lugar al despliegue de lo que tal vez sea el aspecto más interesante de todo el film, que es la particular utilización del espacio y sobre todo la compleja interacción que se genera entre el espacio filmado y el fuera de campo como complemento virtual necesario. Filmar en un espacio estricto (principio de locación única como lo define el propio director), un edificio en Copacabana, permite establecer relaciones complejas entre el singular de cada personaje, de cada situación y algo como un "estado de cosas" de la actualidad. ¿Cómo hablar de religión en Brasil? ¿Recorriendo todo el país? ¿Cómo hablar de favela? ¿Filmando a varias? El abordaje de Coutinho no deja dudas: filmar un espacio delimitado y de allí sacar una visión que evoca un "general", pero no lo representa, ni tampoco lo ejemplifica, aunque logra crear una visión profunda y compleja sobre el Ser brasilero. A partir de la restricción geográfica, la historia y la memoria ganan una sustancia distinta, ligadas a la tierra, a las personas, a sus fabulaciones, a los encuentros, mezcladas, por fin, al cotidiano. Las marcas de diferentes pasados coexisten con el presente sin que esté la necesidad de establecer relaciones causales o de sucesión entre lo que está siendo mostrado. Hay una superposición no cronológica de las historias, un cruce de violencias impuestas a los pobres tanto en el pasado como hoy. El trabajo mal pagado, las actividades más duras, la desocupación, la soledad, el desprecio y los prejuicios de hoy conviven con las marcas de la esclavitud, la miseria y las humillaciones de antaño. De la misma manera, las pequeñas libertades, los pequeños movimientos de creación, "heredadas de inmemoriales inteligencias" surgen en pantalla. Se trata, pues, de un cine del presente, pero no de un presente cronológico e instantáneo, anclado a la actualidad, sino de un presente puro, crónico y ensanchado, que comporta en el los flujos del pasado y del porvenir.

La dimensión del fuera de campo, tanto o más importante que la escena montada en cuadro, es destilada por las anécdotas de los habitantes de cada uno de los departamentos.

¿De dónde vienen? ¿Adónde estuvieron?¿Adónde pertenecen? Un fuera de campo absoluto, exclusivamente actualizado por la palabra, actualización siempre parcial que al mismo tiempo multiplica la virtualidad del espacio exterior, brindándonos una visión múltiple, digresiva de un Brasil que no deja de desterritorializarse y reterritorializarse en una imagen caleidoscópica que nunca termina de cerrarse en una composición orgánica de nación. En este espacio virtual desterritorializado, donde conviven Frank Sinatra, los jugadores de futbol de un club carioca de tercera división y los hijos bastardos de una prostituta adolescente que se define como mitómana compulsiva, pertenecen a una dimensión incierta y descronologizada del tiempo, que funciona como memoria. Pero no es una memoria psicológica como facultad de evocar recuerdos, ni tampoco una memoria colectiva como la de un pueblo existente. Es en cambio la extraña facultad que pone en contacto inmediato el afuera y el adentro, el asunto del pueblo y el asunto privado, el pueblo que falta y el yo que se ausenta, una membrana, un doble devenir. Comunicación del mundo y del yo, en un mundo parcelado, y en un yo roto que no cesan de intercambiarse.

Toda la memoria del mundo se posa sobre cada pueblo oprimido, y toda la memoria del yo se juzga en una crisis orgánica.

Como respuesta al sujeto burgués hegemónico, y preocupado por tener una aproximación que tome totalmente en cuenta la mutable y esencialmente social naturaleza del lenguaje, el lingüista ruso Mikhail Bakhtin discutió con la lingüística saussuriana, ya que ésta, de acuerdo con su perspectiva, define al lenguaje como una entidad 
abstracta, ideal. Para Bakhtin la conciencia individual está moldeada por el lenguaje y, en particular, por el lenguaje oral, el que a su vez es parte de un proceso histórico-social1. Además, añade que el discurso indirecto libre es al mismo tiempo meta-literario y social. Cada vez que un texto expresa el discurso de otro, ya sea de manera directa o indirecta, siempre implica un discurso sobre un discurso, una enunciación sobre una enunciación. La distancia o cercanía entre el narrador y el parlante tiene implicancias tanto sociales como de clase.

Por esto mismo es que siguiendo la perspectiva lingüística del auto ruso, en cuanto a la relación entre la trama y los personajes, el film de Coutinho está mucho más emparentado con lo novelístico que con las formas del relato orgánico clásico. Para Bakhtin la novela, a diferencia de la epopeya o la tragedia, es una forma de relato que ha perdido la unidad colectiva o distributiva por la cual los personajes hablaban un solo y mismo lenguaje. Por el contrario, la novela adopta necesariamente unas veces la lengua corriente anónima, otras la lengua de una clase, de un grupo, de una profesión, otras, la lengua propia de un personaje. Tanto es así que los personajes, las clases, los géneros forman el discurso indirecto libre del autor y el autor forma la visión indirecta libre de aquellos (lo que ellos ven, lo que ellos saben o no saben). Sólo la reflexión en los géneros, anónimos o personificados, constituye a la novela, su "plurilingüismo", su discurso y su visión. El cine moderno toma este aspecto de la novela planteando una línea quebrada, una línea en zigzag que reúne al autor, sus personajes y el mundo, y que pasa entre ellos. De esta forma desarrolla nuevas relaciones con el pensamiento desde tres puntos de vista: el borramiento de un todo o de una totalización de las imágenes en provecho de un afuera que se inserta en ellas; el borramiento del monólogo interior como todo del film en provecho de un discurso y de una visión indirectos libres; el borramiento de la unidad del hombre y el mundo en provecho de una multiplicidad rizomática que no deja de expandirse y tranformarse.

De este punto es desde donde surge esa fascinante intimidad que Coutinho logra con los personajes entrevistados, donde los lleva a desplegar dimensiones complejas y profundas de su "humanidad", creando en el espectador un sentimiento de extraña y profunda empatía.

Y es a partir de estos mecanismos de identificación que emanan las secuencias del film desde donde se pune la categoría "humanidad" entre comillas, ya que la identificación con lo que sucede en la pantalla, no es directamente con el personaje en tanto construcción psicosocial (la prostituta, la pareja de viejos, el ex técnico de fútbol, el ex empresario que cantó con Frank Sinatra) ni tampoco con los tópicos sociológicos que los envuelven (pérdida o encuentro de pareja, la paternidad o maternidad, el advenimiento de la enfermedad, la cercanía a la muerte, la marginación social, etc.) sino que, y este es justamente el logro mayor del film ya que proviene de sus procedimientos estilísticos, hay algo en esos personajes que desborda lo humano, lo antecede o lo sucede, pero que no pertenece a esa categoría, y es allí donde paradójicamente nos reconocemos. En este sentido, el film de Coutinho posee una especie de inmanencia radical. En términos de resultado estético, esa opción por la inmanencia, se revela en una economía narrativa severa, constituida por la ausencia de banda sonora, la ausencia de imágenes ilustrativas, pintorescas o de "cobertura", la negativa en hacer un montaje a partir de temas y, al contrario, sí a partir del flujo de la palabra, y el énfasis sobre el hecho de que el film es el resultado de una negociación entre el cineasta y los entrevistados. Hay una aceptación no resignada del mundo y la negativa en apuntar salidas preconcebidas.

En Edificio Master, muchas veces las realidades abordadas son muy duras, pero las imágenes encuentran de a poco un tono que desplaza esa dureza a un segundo plano. El interés está en la vida cotidiana: las dificultades, 
las pequeñas alegrías, los miedos, los momentos de descanso, los amores, los encuentros, los amigos, la educación y el cuidado de los hijos.

El acercamiento cineasta/personajes se da no a partir del principio de que la vida de ellos es un horror, sino a partir de una mirada generosa, y lo que es fundamental, sin ninguna piedad o compasión condescendiente. Es por eso que la película revitaliza, revelando un síntoma de salud y de vida en medio a una degradación evidente, y muestran un poco de lo que nos puede seguir encantando en ese Brasil sumergido en corrupción, miseria, individualismo e indiferencia. Si el film de Coutinho se aparta de la perspectiva miserabilista, mostrando a la vida de las personas como un horror, él no deja de señalar la dimensión intolerable de lo que estamos viendo. Justamente por no presentar una estructura de causa y efecto o de problema-solución que permite al espectador soportar o tolerar cualquier cosa, lo que hay de inaceptable en las imágenes sigue presente.

¿Cómo se hace cargo entonces Edificio Master de su compromiso político con respecto a lo que John Grierson y Paul Rotha, pioneros de la teoría del documental, denominaban "el mundo histórico"? En este sentido, el film despliega una estrategia muy contemporánea y eficaz en la forma por la cual involucra al espectador con el problema de la lucha de clases.

Lejos de las farragosas estridencias de los discursos militantes que intentan promover una mirada ideológica y orgánica del mundo, que arenga hacia una intervención concreta e inequívoca, la película de Coutinho propone una mirada plena de ambigüedad y complejidad de la cual se construye un modo sumamente original de practicar la etnografía visual. La potencia de este método surge de una carencia originaria: la ausencia de pueblo, situación que ya venía anticipando Gilles Deleuze en la segunda parte de sus estudios sobre cine La Imagen-Tiempo.

Allí, Deleuze notaba que tanto en el período clásico del cine americano como del soviético, el pueblo está ya ahí, real antes de ser actual, ideal sin ser abstracto. De ahí la idea de que como arte de masas el cine puede ser el arte revolucionario o democrático por excelencia, haciendo de las masas un auténtico sujeto. Pero muchos factores iban a comprometer esta creencia: la aparición del hitlerismo que proponía como objeto del cine no ya las masas en condición de sujeto sino las masas sojuzgadas; el estalinismo que sustituía el unanimismo de los pueblos por la unidad tiránica de un partido; la descomposición del pueblo americano, que ya no podía considerarse crisol de pueblos pasados ni germen de un pueblo venidero. Si hubiera un cine político moderno, sería sobre la base: el pueblo ya no existe, o no existe todavía... "el pueblo falta". Esta verdad también sirve para Occidente, pero eran muy escasos los autores que la descubrían, porque estaba oculta bajo los mecanismos de poder y los sistemas de mayoría. Estallaría en cambio en el Tercer Mundo, donde las naciones oprimidas, explotadas, permanecían en estado de perpetuas minorías, con su identidad colectiva en crisis. Lo que acabó con las esperanzas de la toma de conciencia fue justamente la toma de conciencia de que no había pueblo, sino siempre varios pueblos, una infinidad de pueblos que quedaban por unir o bien que no había que unir, para que el problema cambiara. El pueblo no existe más que en estado de minoría y por eso falta.

Y es justamente en este punto donde surge la paradoja más interesante en cuanto a la aproximación etnocinemática de este film: si entendemos a la etnografía como práctica de acuerdo a su etimología (etnos = pueblo o tribu y grafos = descripción escrita) ¿Se puede hablar de etnografía en relación a un pueblo que no existe? Es aquí donde poéticas como la de Coutinho subvierten creativamente la relación entre la tecnología audiovisual y la práctica etnográfica para formular un nuevo dispositivo de conocimiento: ya no se trata de una cámara que 
registra (grafos) a un pueblo (etnos) que pre-existe, sino que ahora es una cámara que como dispositivo de escritura crea a un pueblo allí donde no estaba. Se trata entonces de un caso de inscripción étnica como subversión a la tradicional etnografía fílmica. De esta manera se da la máxima que le da el título al notable libro de Jean Louis Comolli: el cineasta, cuando cumple con su verdadera labor como documentalista ya no ve para filmar, sino que filma para ver.

Notas

1. "La evolución de la conciencia individual depende de la evolución del lenguaje, en sus estructuras gramaticales así como en sus estructuras ideológicas concretas. La personalidad evoluciona junto con el lenguaje. La evolución del lenguaje, es un elemento en la evolución de la comunicación social y no puede ser separado de esta ni de sus bases materiales.

Las bases materiales determina la estratificación de la sociedad, su estructura socio política, y divide a los individuos jerárquicamente en relaciones de interacción. Estos son los elementos que engendran el lugar, el momento, las condiciones, las formas, y los medios de la comunicación verbal. A su vez, estos últimos determinan los destinos de la enunciación individual en un momento dado de la evolución del lenguaje". Fragmento extraído de El marxismo y la filosofía del lenguaje, pp. 211-212.

Bibliografía

Peirano, M. A favor de la etnografía.

Guber, R. La entrevista antropológica.

Reguillo, R. El otro antropológico. Poder y representación en una contemporaneidad sobresaltada.

Appadurai, A. La modernidad desbordada.

Krotz, E. Alteridad y pregunta antropológica.

Deleuze, G. La Imagen-Tiempo.

Pasolini, P. P. Manifiesto para un nuevo teatro.

Niney, F. El documental y sus falsas apariencias.

Nichols, B. La representación de la realidad.

Comolli, J. L. Filmar para ver.

Bakhtin, M. El Marxismo y la filosofía del lenguaje.

Da Silva, M. A. Eduardo Coutinho e o cinema etnográfico para além da Antropologia.

Lins, C. El cine de Eduardo Coutinho: un arte del presente. 
Abstract:

The article analyzes the indissoluble link between the body and the word spoken as a speech producer of meaning in the audiovisual media. The field of study of this paper will be the film Master Building (2002) by Brazilian director Eduardo Coutinho considered as a superlative example regarding the use of interviews in a documentary film and as therethrough arise from the characters interviewed dimensional sense of unusual depth and complexity that transcend the common place and stereotypes that are commonly associated with this resource. Finally, on reflect on this particular form of interview as the cornerstone of modern audiovisual ethnography and its impact on contemporary epistemology thinking and analyzing the documentary film.

Key words: documentary cinema - interview - etnography - audiovisual - Coutinho.

\section{Resumo:}

O artigo trata a relação inseparável entre o corpo e a palavra dita como discurso produtor de sentido no meio audiovisual. O campo de estudo desta elaboração será o filme Edifício Máster (2002) do diretor brasileiro Eduardo Coutinho, exemplo superlativo do uso do dispositivo da entrevista num filme documental, e como, através dele, surgem dos personagens entrevistados dimensões de sentido de uma profundidade e complexidade excepcionais que transcendem os lugares comuns e estereótipos associados a este recurso. Finalmente, reflexiona-se sobre esta modalidade particular de entrevista como a pedra angular da etnografia audiovisual moderna e seu impacto na epistemologia contemporânea que pensa e analisa o cinema documental.

Palavras chave: cinema documental - entrevista - etnografia audiovisual - Coutinho.

Edificio Master: la tecnología audiovisual como escritura étnica fue publicado de la página 65 a página75 en Cuadernos del Centro de Estudios de Diseño y Comunicación № 62 